\title{
KEANEKARAGAMAN JENIS DAN KELIMPAHAN IKAN GELODOK (Periopthalmus sp.) DI KAWASAN MANGROVE PANTAI KERTOMULYO PATI JAWA TENGAH
}

Wulan Isrotul Asmi ${ }^{1}$, Eko Retno Mulyaningrum² ${ }^{2}$, Lussana Rossita Dewi ${ }^{3}$ Pendidikan Biologi FPMIPATI Universitas PGRI Semarang, Indonesia wulanisrotul24@gmail.com, ekoretno@upgris.ac.id, lussanarossitadewi@upgris.ac.id

\begin{tabular}{|c|c|}
\hline Received: & 02-02-2022 \\
\hline Accepted: & 03-02-2022 \\
\hline Published: & 20-02-2022 \\
\hline Keywords: & $\begin{array}{l}\text { periopthalmus } \\
\text { sp., diversity, } \\
\text { abundance. }\end{array}$ \\
\hline
\end{tabular}

Abstract

Periopthalmus $s p$. is one type of biota that likes an environment with mud and mangrove forests. This study aims to determine the species diversity and abundance of Periophalmus sp. in the mangrove area of Kertomulyo Pati beach. Sampling Periopthalmus sp. carried out in the morning when the sea water is receding, take the fish manually by using a hand and other auxiliary tools such as nets and fish scoops. The results showed that there were 386 individuals of fish, 2 genera and 4 species, the abundance of Periothalmus sp. The high category was Baleopthalmus pectinirostris 139 individuals, while the low category was Periopthalmodon schloresseri 14 individuals. The diversity index obtained is 1.238, which means that the results of the study show that the level of diversity of gelodok fish in the mangrove area of Kertomulyo Pati beach is included in the medium criteria. Meanwhile, the level of dominance of gelodok fish is obtained at 0.31 which is included in the medium category, so there is no dominant species, this shows that the productivity of the waters is quite balanced between predators and prey. The results of the measurement of soil $\mathrm{pH}$ ranged from 6.1 to 6.5 and had a type of mud substrate which was a habitat type according to Periopthalmus sp.

\begin{tabular}{ll}
\hline Kata & periopthalmus \\
kunci: & sp., \\
& keanekaragaman, \\
& kelimpahan.
\end{tabular}

\section{Abstrak}

Periopthalmus $s p$. merupakan salah satu jenis biota yang menyukai lingkungan yang bersubrat lumpur dan hutan mangrove. Penelitian ini bertujuan untuk mengetahui keanekaragaman jenis dan kelimpahan Periophalmus sp. di kawasan mangrove pantai Kertomulyo Pati. Pengambilan sampel menggunakan metode Purposive Sampling, pengambilan sampel Periopthalmus sp. dilakukan pada saat pagi hari dimana air laut sedang surut, mengambil ikan secara manual yaitu menggunakan tanggan dan alat pembantu lainya seperti jarring dan serok ikan. Hasil penelitian terdapat jumlah ikan sebanyak 386 individu, terdapat 2 genus dan 4 spesies, kelimpahan Periothalmus sp. yang memiliki kategori tinggi adalah Baleopthalmus pectinirostris 139 individu, sedangkan kategori rendah adalah Periopthalmodon schloresseri 14 individu. Indeks keanekaragaman yang diperoleh sebesar 1, 238 yang berarti bahwa hasil penelitian menunjukan tikat keanekaragaman ikan gelodok di kawasan mangrove 
pantai Kertomulyo Pati termasuk dalam kriteria sedang. Sedangkan untuk tingkat dominasi ikan gelodok diperoleh sebesar o,31 yang termasuk dalam kategori sedang maka tidak ada spesies yang mendominasi, hal ini menunjukan produktivitas perairan tersebut cukup seimbang antara predator dan mangsa. Hasil pengukuran $\mathrm{pH}$ tanah berkisar 6,1- 6,5 dan memiliki tipe bersubstrat lumpur yang merupakan tipe habitat sesuai Periopthalmus sp.

Corresponding Author: Wulan Isrotul Asmi E-mail: wulanisrotul24@gmail.com

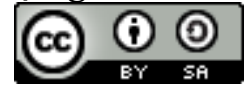

\section{PENDAHULUAN}

Ekosistem mangrove adalah salah satu lingkungan yang paling penting dan produktif untuk jenis perikanan, di daerah tropis dan muara subtropis yang meningkatkan kesuburan dan produktivitas daerah pesisir (Sellang \& Pi, 2020). Hutan mangrove kaya akan bahan organik yang berasal dari sisa-sisa tanaman mangrove yang telah membusuk atau kotoran hewan dan kemudian berdampak dalam menurunkan $\mathrm{pH}$ substrat menjadi lebih asam (Karil, Yusuf, \& Maslukah, 2015).

Periopthalmus sp. merupakan anggota dari family Gobiidae subfamily Oxudercinae. Periopthalmus $s p$. termasuk jenis ikan amphibious yang dapat menggunakan sirip pertoralnya untuk berjalan di atas tanah (Swanson \& Gibb, 2004). Sebagai amphibious ikan ini dapat menyesuaikan diri secara unik ke habitat intertidal. Periopthalmus sp. merupakan hewan yang hidup di lingkungan panas, hutan mangrove dan dataran berlumpur (Sunarni \& Maturbongs, 2017). Periopthalmus sp. berperan dalam hutan mangrove karena dapat mentoleransi subtrat dengan kadar garam yang rendah (Redjeki, 2014). Penelitian Periopthalmus sp. ini sangat sedikit sehingga untuk mengetahui apa saja jenis spesies Periopthalmus sp. sangat susah, dalam penelitian (Eprilurahman et al., 2018) di Pantai Bali Desa Masjid Lama Kecamatan Talawi Kabupaten Batu Bara menemukan 4 jenis Periopthalmus sp. yaitu Boloephthalmus bodarti, Periphthalmodon scholesseri, Periophthalmus chrysospilos dan Periophthalmus gracilis.

Penelitian ini bertujuan untuk mengetahui jenis dan kelimpahan Periopthalmus sp. karena belum adanya penelitian mengenai jenis dan kelimpahan Periopthalmus $s p$. di kawasan mangrove pantai Kertomulyo Pati manfaat dari penelitian ini dapat dijadikan bahan untuk penelitian lanjutan serta menambah referensi mengenai jenis dan kelimpahan ikan gelodok di kawasan mangrove pantai Kertomulyo Pati.

\section{METODE PENELITIAN \\ Subjek Penelitian} mangrove.

Subjek penelitian adalah Ikan Gelodok (Periopthalmus sp.) yang berada pada habitat

\section{Tempat dan waktu penelitian}

Penelitian ini dilaksanakan pada bulan Maret-April 2021 dengan dua stasiun yaitu pada aliran sungai dan tepi pantai pada kawasan mangrove pantai Kertomulyo,Kecamatan Trangkil, Kabupaten Pati.

\section{Alat dan bahan}

Alat yang digunakan dalam penelitian yaitu Kamera, meteran, alat tulis, coolbox, label, patok/pasak, pisau, gunting, tali rafia, jaring ikan, serok ikan, suhu air, $\mathrm{pH}$ air, $\mathrm{pH}$ tanah dan kelembapan tanah. Bahan yang digunakan dalam penelitian yaitu ikan gelodok (Periopthalmus sp.). 


\section{Rancangan Penelitian}

Penetapan lokasi penelitian pengambilan sampel dilakukan dengan metode Purposive Sampling yaitu teknik yang digunakan apabila sampel yang akan diambil memiliki pertimbangan tertentu (Sugiyono, 2019). Peneliti menggunakan metode ini karena lokasi mangrove pantai Kertomulyo Pati merupakan tempat wisata sehingga terdapat adanya aktivitas masyarat dan tidak semua lokasi mangrove terdapat ikan gelodok. Peneliti memilih stasiun I aliran sungai dan stasiun II tepi pantai. Pengambilan sampel ikan gelodok dilakukan pada saat air surut dan dilakukan pengukuran factor ekologi pada habitat ikan gelodok (Periopthalmus sp.).

\section{Analisis data}

Analisis data untuk menghitung keanekaragaman jenis menggunakan rumus Indeks Keanekaragaman Jenis (H') Shanon-Wiener, Kemerataan jenis (E) dihitung menggunakan rumus Indeks Evennes, Dominasi dihitung menggunakan rumus Indeks dominasi dari Simpson dan menghitung indeks kelimpahan relavite menggunakan rumus Indeks Nilai Penting.

\section{HASIL DAN PEMBAHASAN}

Berdasarkan hasil penelitian jumlah ikan gelodok yang ditemukan di kawasan mangrove pantai Kertomulyo Pati, terdiri dari 4 jenis dan 380 individu yang terbagi dalam satu family, tiga genus dan empat spesies. Genus terbanyak adalah Boleopthalmus yaitu sebanyak dua spesies dengan jumlah 277 spesies, dimana masing-masing spesies terdiri dari Boleopthalmus boddarti yang berjumlah 138 individu dan Boleopthalmus pectinirostris berjumlah 139 individu. Selanjutnya disusul oleh genus Periopthalmus satu spesies dengan jumlah 89 individu, dan Periophthalmodon satu spesies dengan jumlah 14 individu.

Genus Boleopthalmus jumlah individu paling banyak karena jenis ini menghabiskan waktunya berendam di lumpur dan senang melompat-lompat pada saat melakukan aktifitas, jadi penangkapan lebih banyak, dan memiliki sarang yang berada di daerah pasang surut mundah untuk mengambil dalam sarangnya, didukung dengan pernyataan (Maturbongs, Elviana, Sunarni, \& deFretes, 2018) bahwa genus Boleopthalmus dalam sarang yang berbentuk saluran-saluran didalam substrat dengan kedalaman antara 40-100 cm sedangkan hasil tangkapan Periopthalmodon schlosseri paling sedikit karena pada lokasi penelitian tidak terlihat jenis Periopthalmodon schlosseri berada pada permukaan lumpur, karena termasuk ikan yang endemis sehingga tidak dapat ditemui disembarang tempat (Maturbongs et al., 2018).

Indeks keanekaragaman jenis digunakan untuk mengetahui tingkat keanekaragaman jenis menggunakan Shanon-Wiener. Indeks keanekaragaman jenis Periopthalmus sp. di Kawasan Mangrove Pantai Kertomulyo Pati tersaji pada tabel 1. berikut ini:

Tabel 1. Indeks keanekaragaman Periopthalmus sp. yang ditemukan
\begin{tabular}{llll} 
No & Stasiun & Nilai H' & Kriteria \\
\hline 1 & I & 1,238 & Sedang \\
\hline 2 & II & 1,097 & Sedang \\
\hline
\end{tabular}

Berdasarkan tabel 1. menunjukan nilai Periopthalmus sp. di Kawasan Mangrove Pantai Kertomulyo Pati masing - masing stasiun menunjukan nilai lebih dari satu, yang artinya termasuk kategori sedang. Indeks stasiun I dan II terdapat dalam kategori sedang, dimana tempat tersebut memiliki habitat pasang surut yang terlau tinggi. Pasang surut air laut yang tinggi mempengaruhi ketersedian fiktoplankton sebagai pakan Periopthalmus sp., sedangkan pada saat kondisi surut Periopthalmus sp. aktif mencari makan dan berinteraksi satu sama lain untuk mempertahankan wilayah (Ningsih \& Santoso, 2020).

Indeks kemerataan jenis berfungsi untuk mengetahui kemerataan setiap jenis dalam komunitas yang dijumpai. Kemerataan menunjukan derajat kemerataan individu antar 
Wulan Isrotul Asmi, Eko Retno Mulyaningrum, Lussana Rossita Dewi

Keanekaragaman Jenis dan Kelimpahan Ikan Gelodok (Periopthalmus sp.) di Kawasan

Mangrove Pantai Kertomulyo Pati Jawa Tengah

spesies. Indeks kemerataan jenis ikan gelodok di Kawasan Mangrove Pantai Kertomulyo Pati tersaji pada tabel 2. berikut ini:

Tabel 2. Indeks kemerataan ikan gelodok yang ditemukan

\begin{tabular}{llll} 
No & Stasiun & Nilai E & Kriteria \\
\hline 1 & I & 0,893 & Merata \\
\hline 2 & II & 1,128 & Merata \\
\hline
\end{tabular}

Berdasarkan tabel 2. menunjukan nilai Periopthalmus sp. di Kawasan Mangrove Pantai Kertomulyo Pati termasuk merata. kriteria tersebut menunjukan bahwa setiap individu memiliki jumlah individu yang sama antar jenis dalam stasiunya.

Indeks dominasi jenis berfungsi untuk menentukan jenis ikan gelodok yang dominan dalam suatu lokasi penelitian. Nilai tiap jenis ikan gelodok yang ditemukan berbeda tiap stasiunya. Adapun nilai ikan gelodok di Kawasan Mangrove Pantai Kertomulyo Pati tersaji pada tabel 3. berikut ini:

Tabel 3. Indeks dominasi ikan gelodok yang ditemukan
\begin{tabular}{llll}
\hline No & Stasiun & C & Kriteria \\
\hline 1 & I & 0,31 & Sedang \\
\hline 2 & II & 0,24 & Sedang \\
\hline
\end{tabular}

Berdasarkan tabel 3. menunjukan nilai ikan gelodok pada masing-masing stasiun di Kawasan Mangrove Pantai Kertomulyo Pati termasuk sedang kisaran ikan gelodok adalah o,24 - 0,31. Dominasi jenis pada suatu perairan terjadi karena kompetisi pakan dan perubahan lingkungan tidak seimbang antara predator dan mangsa sehingga terjadinya kompetisi antar jenis (Modesta dkk, 2018). Perairan mangrove pantai Kertomulyo Pati dominasi ikan gelodok termasuk dalam kategori sedang maka tidak ada spesies yang mendominasi hal ini menunjukan produktivitas perairan tersebut cukup seimbang antara predator dan mangsa.

Tabel 4. Kelimpahan Periopthalmus sp. di Kawasan Mangrove Pantai Kertomulyo Pati

\begin{tabular}{|c|c|c|c|}
\hline Stasiun & Jenis Ikan Gelodok & Jumlah & (\%) ${ }^{\text {IKR }}$ \\
\hline \multirow[t]{5}{*}{$\mathrm{I}$} & Boleopthalmus boddarti & 71 & 34,47 \\
\hline & Boleopthalmus pectinirostris & 76 & 36,89 \\
\hline & Periophthalmodon schlosseri & 12 & 5,83 \\
\hline & Periopthalmus argentilineatus & 47 & 22,82 \\
\hline & $\sum$ Ikan Gelodok & 206 & 100 \\
\hline \multirow[t]{5}{*}{ II } & Boleopthalmus boddarti & 67 & 38,51 \\
\hline & Boleopthalmus pectinirostris & 63 & 36,21 \\
\hline & Periophthalmodon schlosseri & 2 & 1,15 \\
\hline & Periopthalmus argentilineatus & 42 & 24,14 \\
\hline & $\sum$ Ikan Gelodok & 174 & 100 \\
\hline
\end{tabular}

Pada tabel 4. menunjukan hasil nilai (IKR) masing-masing jenis ikan gelodok pada setiap stasiun. Hasil penelitian yang sudah dilakukan saat pengambilan data kelimpahan Periopthalmus sp. di Kawasan Mangrove Pantai Kertomulyo Pati memilik dua stasiun penelitian memiliki kelimpahan bervariasi setiap stasiun. Kelimpahan dapat dikelompokan 
Wulan Isrotul Asmi, Eko Retno Mulyaningrum, Lussana Rossita Dewi

Keanekaragaman Jenis dan Kelimpahan Ikan Gelodok (Periopthalmus sp.) di Kawasan

Mangrove Pantai Kertomulyo Pati Jawa Tengah

menjadi lima : a) sangat jarang (o - 2\%), b) kadang-kadang (20 - 40\%), c) sering atau tidak banyak (40-60\%), d) banyak atau berlimpah-limpah (60-80\%), dan e) sangat banyak atau sangat berlimpah $(80-100 \%)$. Berdasarkan hasil pengamatan kelimpahan ikan gelodok tertinggi adalah jenis Baleopthalmus boddarti 38,51\% termasuk dalam ketegori kadangkadang, dan kelimpahan yang terendah adalah jenis Periophthalmodon schlosseri yakni hanya sebesar $1,15 \%$ termasuk dalam kategori sangat jarang, dari data yang di dapat yang menjadi salah satu faktor yang mempengaruhi keanekaragaman adalah, vegetasi, ketinggian, cuaca lingkungan (suhu dan kelembapan). Keadaan faktor fisik kimia di lokasi penelitian dapat diperhatikan pada tabel 5 . berikut ini :

Tabel 5. Parameter Fisik Kimia di Kawasan Mangrove Pantai Kertomulyo Pati

\begin{tabular}{ccc}
\hline Parameter lingkungan & \multicolumn{2}{c}{ Lokasi } \\
\cline { 2 - 3 } & $\begin{array}{c}\text { Stasiun I } \\
\text { (aliran sungai) }\end{array}$ & $\begin{array}{c}\text { Stasiun II } \\
\text { (tepi pantai) }\end{array}$ \\
\hline PHtanah & $6,1-6,5$ & $6-6,2$ \\
\hline PHair & 7,1 & 7,1 \\
\hline Kelembapan & 8 & 8 \\
\hline Suhu air & $28,1-28,6$ & $28,1-28,2$ \\
\hline
\end{tabular}

Dari data parameter fisik kimia di kawasan mangrove pada Boleopthalmus pectinirostris dan Periopthalmodon schlosseri memiliki pH tanah rata-rata 6-6,5, pH air 7,1, kelembapan 8, dan suhu air rata-rata 28,1 dengan subtrat tanah berlumpur, namun dari kedua spesies memiliki perbedaan dimana Boleopthalmus pectinirostris jumlah individu paling banyak karena jenis ini menghabiskan waktunya berendam di lumpur dan senang melompatlompat pada saat melakukan aktifitas, jadi penangkapan lebih banyak, dan memiliki sarang yang berada di daerah pasang surut mundah untuk mengambil dalam sarangnya, didukung dengan pernyataan (Sunarni \& Maturbongs, 2017) bahwa ikan gelodok genus Boleopthalmus dalam sarang yang berbentuk saluran-saluran didalam substrat dengan kedalaman antara 40$100 \mathrm{~cm}$. Namun hasil tangkapan Periopthalmodon schlosseri paling sedikit karena pada lokasi penelitian tidak terlihat jenis Periopthalmodon schlosseri berada pada permukaan lumpur, termasuk ikan yang endemis sehingga tidak dapat ditemui disembarang tempat (Maturbongs et al., 2018).

Penelitian (Hidayaturrahmah \& Muhammat, 2013) menyatakan tidak semua wilayah di mangrove menjadi habitatnya, sumber pakan Peripohthalmodon schlosseri adalah kepiting hal ini di dukung oleh keberadaan sarang dan aktivitasnya berdekatakan dengan sarang dan aktivitas kepiting, ditemukan cangkang kepiting dalam sarang Peripohthalmodon schlosseri. Memiliki ukuran besar daripada ikan gelodok spesies lainya sering disebut giant muddskiper. Peripohthalmodon schlosseri dapat menjaga metabolisme saat berada di dalam lumpur dengan kadar oksigen rendah (Aguilar, Ishimatsu, Ogawa, \& Huat, 2000). Daerah mangrove pantai Kertomulyo Pati memiliki parameter fisika kimia dapat dilihat pada tabel 5. Parameter fisika dan kimia mempengaruhi kehidupan ikan gelodok.

Suhu air dari kedua stasiun ini sesuai bagi kehidupan ikan gelodok yang berkisaran ratarata $28^{\circ} \mathrm{C}$, suhu menjadi faktor penting untuk daya tarik ikan gelodok atau beberapa biota lainya, karena suhu berpengaruh dalam pertumbuhan dan kematian dan suhu kisaran 24$29^{\circ} \mathrm{C}$ sesuai untuk pertumbuhan ikan (Sunarni \& Maturbongs, 2017). Ikan gelodok memiliki toleransi terhadap perubahan suhu, sehingga suhu perairan juga merupakan salah satu indikator lingkungan yang mempengaruhi sebaran dan keanekaragaman jenis ikan gelodok. Sedangkan untuk kisaran $\mathrm{pH}$ air pada kedua stasiun rata-rata berkisaran 7,1, oleh sebab itu perairan pantai Kertomulyo Pati mempunyai $\mathrm{pH}$ yang mendukung kehidupan ikan gelodok. Menurut (Effendi, 2003) sebagian besar biota akuatik menyukai nilai ph 7-8,5.

Keasaman $\mathrm{pH}$ tanah dari kedua stasiun penelitian berkisaran rata-rata 6,1 yang bertanda bahwa $\mathrm{pH}$ tanah sesuai dengan kisaran $\mathrm{pH}$ substrat habitat ikan gelodok yang berkisaran $5,8-8,2)$. pH substart sangat mempengaruhi daya tahan organisme yang hidup di dasar perairan baik yang bersifat infauna maupun epifauna 


\section{KESIMPULAN}

Keanekaragaman ikan gelodok yang ditemukan menunjukan jenis dan jumlah individu berbeda tiap stasiun. Ikan gelodok yang ditemukan di lokasi penelitian sebanyak 4 jenis dengan jumlah 380 ekor. Ikan gelodok yang ditemukan terdiri dari tiga genus yaitu genus Baleopthalmus, genus Periophthalmodon dan genus Periopthalmus. Sedangkan ikan gelodok genus Boleopthalmus merupakan ikan gelodok yang paling banyak ditemukan sebanyak 2 jenis dengan jumlah individu 277 ekor. Kelimpahan ikan gelodok termasuk dalam kategori kadang-kadang factor yang mempengahuri adalah ketersiadaan makanan karena untuk parameter fisika dan kimia pada kawasan mengrove pantai kertomulyo pati sudah memenuhi kriketia jenis habitat ikan gelodok.

\section{BIBLIOGRAFI}

Aguilar, Nancy M., Ishimatsu, Atsushi, Ogawa, Kogi, \& Huat, Khoo Khay. (2000). Aerial ventilatory responses of the mudskipper, Periophthalmodon schlosseri, to altered aerial and aquatic respiratory gas concentrations. Comparative Biochemistry and Physiology Part A: Molecular \& Integrative Physiology, 127(3), 285-292. Google Scholar

Effendi, Hefni. (2003). Telaah kualitas air bagi pengelolaan sumberdaya dan lingkungan perairan. Google Scholar

Eprilurahman, Rury, Asti, Hastin Ambar, Hadisusanto, Suwarno, Yudha, Donan Satria, Ramadani, Ratna Sari, Pranoto, F. X. Sugiyo, \& Muhtianda, Iman Akbar. (2018). KEKAYAAN FAUNA GIANYAR, BALI: Udang, Ikan, Amfibi, Reptil, Burung dan Mamalia. UGM PRESS. Google Scholar

Hidayaturrahmah, Hidayaturrahmah, \& Muhammat, Muhammat. (2013). Habitat ikan timpakul (Periophthalmodon schlosseri) di Muara Sungai Barito. EnviroScienteae, 9(3), 134-139. Google Scholar

Karil, Ahmad Romdhoni Fauzan, Yusuf, Muh, \& Maslukah, Lilik. (2015). Studi sebaran konsentrasi nitrat dan fosfat di perairan Teluk Ujungbatu Jepara. Journal of Oceanography, 4(2), 386-392. Google Scholar

Maturbongs, Modesta Ranny, Elviana, Siska, Sunarni, Sunarni, \& deFretes, Dominggus. (2018). Studi keanekaragaman ikan gelodok (Famili: Gobiidae) pada muara Sungai Maro dan Kawasan Mangrove Pantai Kembapi, Merauke. Depik, 7(2), 177-186. Google Scholar

Ningsih, Apria, \& Santoso, Hari. (2020). KEANEKARAGAMAN IKAN GELODOK (MUDSKIPPER) DI HUTAN MANGROVE KECAMATAN UJUNG PANGKAH KABUPATEN GRESIK. JURNAL ENGGANO, 5(3), 367-376. Google Scholar

Redjeki, Sri. (2014). Komposisi dan Kelimpahan Ikan di Ekosistem Mangrove di Kedungmalang, Jepara. Indonesian Journal of Marine Sciences/Ilmu Kelautan, 18(1). Google Scholar

Sellang, Haerunnisa, \& Pi, S. (2020). Biologi Perairan. Penerbit Lakeisha. Google Scholar

Sugiyono. (2019). Metode Penelitian Kuantitatif, Kualitatif dan R\&D. Bandung: Alfabeta. Google Scholar

Sunarni, Sunarni, \& Maturbongs, Modesta R. (2017). Biodiversitas dan Kelimpahan Ikan Gelodok (Mudskipper) di Daerah Intertidal Pantai Payumb, Merauke. Prosiding 
Wulan Isrotul Asmi, Eko Retno Mulyaningrum, Lussana Rossita Dewi

Keanekaragaman Jenis dan Kelimpahan Ikan Gelodok (Periopthalmus sp.) di Kawasan

Mangrove Pantai Kertomulyo Pati Jawa Tengah

Seminar Nasional Kemaritiman Dan Sumber Daya Pulau-Pulau Kecil, 1(1). Google $\underline{\text { Scholar }}$

Swanson, Brook O., \& Gibb, Alice C. (2004). Kinematics of aquatic and terrestrial escape responses in mudskippers. Journal of Experimental Biology, 207(23), 4037-4044. Google Scholar 